\title{
SISTEMA DE COTAS E FRAUDES EM UMA UNIVERSIDADE FEDERAL BRASILEIRA
}

\section{QUOTA SYSTEM AND FRAUD IN A BRAZILIAN FEDERAL UNIVERSITY}

\author{
Sales Augusto dos Santos ${ }^{1}$, Matheus Silva Freitas ${ }^{2}$ \\ ${ }^{1}$ Universidade de Brasília (UnB), Instituto Nacional de Ciência e Tecnologia de Inclusão no Ensino e \\ na Pesquisa (INCTI), Brasil, E-mail: salesaugustodossantos@gmail.com,
} ORCID: https://orcid.org/0000-0002-0856-6653

2 Universidade Federal de Minas Gerais (UFMG), Programa de Pós-Graduação em Educação (PPGE) da Faculdade de Educação (FaE), Brasil, E-mail: freitassmat@gmail.com

ORCID: https://orcid.org/0000-0001-6245-9085

\author{
ART ICLE INFO \\ Article history: \\ Received 2020-04-11 \\ Accepted 2020-06-20 \\ Available online $2020-06-20$
}

Palavras-chave: Cursos de alto prestígio; sistema de cotas; subcotas Étnico-raciais; fraudes; mulheres pretas.

Keywords: High prestige courses; quota system; ethnic-racial sub-quotas; frauds; black women.

RESUMO. Neste artigo são apresentados alguns resultados de uma pesquisa financiada pelo Programa Institucional de Bolsas de Iniciação Científica - PIBIC/CNPq-2017/2018. A investigação visava a pesquisar o impacto, em sentido amplo, do ingresso de estudantes subcotistas étnico-raciais na Universidade Federal de Viçosa (UFV), mas em alguns de seus cursos de alto prestígio, a saber: Agronomia, Direito, Engenharia Mecânica, Engenharia Química, Medicina e Medicina Veterinária. O período pesquisado, do primeiro semestre de 2013 ao segundo semestre de 2016, refere-se ao prazo para o cumprimento integral do disposto na Lei 12.711/2012, que determinou a implantação do sistema de cotas nas universidades federais brasileiras. Constatou-se, por um lado, que houve o ingresso fraudulento de estudantes brancos/as nas subcotas étnicoraciais destinadas a estudantes pretos/as, pardos/as e indígenas. Por outro lado, e em consequência das fraudes, a pesquisa também evidenciou a pouca presença de estudantes negras (pretas e pardas) nos cursos supracitados, mesmo após a implementação de uma política pública que tinha como objetivo aumentar a presença dessas estudantes na universidade.

ABSTRACT. This paper presents a few results of a research funded by PIBIC/CNPq-2017/2018, the Institutional Program for Scientific Research Scholarships. The investigation intended to research the broadly defined impact of the entry of students through the ethno-racial subquota system in Universidade Federal de Viçosa (UFV), with a focus on high-prestige majors, i.e.: Agronomy, Law, Mechanical Engineering, Chemical Engineering, Medicine and Veterinary Medicine. The researched time period, from the first semester of 2013 to the second semester of 2016, refers to the deadline for integral implementation of what's laid out in Law 12.711/2012, determining the quota system in Brazilian federal universities. On one hand, it was verified that there were fraudulent admissions of white students through ethno-racial subquotas destined for Black (pretos/as), brown (pardos/as) and indigenous (indígenas) students. On the other hand, as a consequence of fraud, the research also showed the small presence of Black (negras, including pretas and pardas) female students in the aforementioned majors, even after the implementation of a public policy intended to increase their presence in the university. 


\section{Introdução}

De acordo com a professora e pesquisadora da Fordham University, Tanya Katerí Hernández (2017), desde o começo século XXI está havendo implementação de políticas de ação afirmativa para ingresso de estudantes em universidades, baseadas na cor/raça dos/as discentes, em alguns países da América Latina, como, por exemplo, no Brasil, na Colômbia, no Equador, no Uruguai e em Honduras. Para a professora Hernández (2017, p. 29, 139), o Brasil tem se destacado na América Latina e, consequentemente, tornou-se uma referência para outros países da região no que diz respeito à implementação dessas políticas. Segundo a autora, "o uso bem-sucedido de políticas de ação afirmativa no Brasil pode servir como uma inspiração para que outros países latino-americanos também melhorem antigos padrões de desigualdade racial" (HERNÁNDEZ, 2017, p. 149). Porém, a pesquisadora Hernández (2017, p. 147) não deixa de reconhecer a existência de fraudes praticadas por estudantes brancos/as nas políticas de ação afirmativa brasileiras destinadas aos estudantes pretos/as, pardos/as e indígenas, fato que também constatamos em nossa pesquisa, como veremos neste artigo. ${ }^{1}$

Nele apresentamos alguns resultados da pesquisa "Ingresso e presença de estudantes negros/as cotistas nos cursos de alto prestígio da Universidade Federal de Viçosa (UFV)"2, entre os quais destacamos dados que indicam a pouca presença de estudantes mulheres pretas nesses cursos, em razão de fraudes praticadas por estudantes brancos/as. Em geral, tais estudantes praticam esse crime nas subcotas étnico-raciais estabelecidas pela Lei no 12.711/2012, a chamada Lei das Cotas, autodeclarando-se pardos/as (cf. NUNES; SANTOS, 2019; DIAS; TAVARES JÚNIOR, 2018).

A pesquisa teve como objetivo investigar a repercussão, em sentido amplo, do ingresso de estudantes cotistas que ingressaram na UFV por meio das subcotas étnico-raciais em seis cursos que são considerados de alto prestígio na universidade, a saber: Agronomia, Direito, Engenharia Mecânica, Engenharia Química, Medicina e Medicina Veterinária, no período de 2013 a 2016. Essa delimitação temporal se justifica pelo fato de que foi somente a partir do ano de 2013 que a UFV começou a implementar o sistema de cotas para estudantes de escolas públicas, em razão da determinação da Lei Federal no 12.711/2012, de 29 de agosto de 2012.

\footnotetext{
${ }^{1}$ Ao analisarmos a ocorrência de fraudes no sistema de cotas da UFV, mostraremos que o Brasil talvez não possa servir de referência ou modelo perfeito para outros países da América Latina no que se refere à implementação de políticas de ação afirmativa baseada na cor/raça dos/as estudantes, visto que não foi somente na UFV que houve fraudes no sistema de cotas, mas em muitas universidades brasileiras, como, por exemplo, na Universidade Federal de Pelotas (UFPel), na Universidade Federal do Rio Grande do Sul (UFRGS), na Universidade Federal de Minas Gerais (UFMG), na Universidade de Brasília (UnB), entre outras importantes Instituições Federais de Ensino Superior (IFES), conforme demonstraram Nunes e Santos (2019).

${ }^{2}$ Esta pesquisa foi financiada pelo Programa Institucional de Bolsas de Iniciação Científica - PIBIC/CNPq 2017/2018.
} 
Contudo, a implementação desse sistema foi gradativa, visto que as Instituições Federais de Ensino Superior (IFES), não tinham obrigação de implementá-lo integralmente no seu primeiro ano de existência ou nos dois anos subsequentes. A implementação completa do sistema foi obrigatória a partir do ano de 2016. Conforme estabeleceu o art. 8으 da Lei no 12.711/2012, as IFES vinculadas ao Ministério da Educação deveriam "implementar, no mínimo, 25\% (vinte e cinco por cento) da reserva de vagas prevista nesta Lei, a cada ano, e terão o prazo máximo de 4 (quatro) anos, a partir da data de sua publicação, para o cumprimento integral do disposto nesta Lei" (BRASIL, 2012a). Portanto, este marco temporal foi um dos motivos para delimitarmos a pesquisa até o ano de 2016.

Deve-se destacar que, por um lado, antes da mencionada lei raramente as universidades públicas federais brasileiras tinham discentes pretos/as, pardos/as e indígenas em cursos considerados de alto prestígio (cf. QUEIROZ, 2004; QUEIROZ, 2002). Por outro lado, pesquisas recentes mostram que após a implementação do sistema de cotas para estudantes de escolas públicas, com subcotas para estudantes pretos, pardos, indígenas e deficientes, começou a haver mudanças na composição racial dos/as estudantes das universidades federais (ANDIFES, 2019; FERES JÚNIOR; DAFLON, 2014).

Todavia, essas mudanças não ocorrem sem resistências e tentativas de fraudes no sistema de cotas por parte de alguns/mas estudantes brancos/as, como indicam outros estudos e pesquisas (NUNES; SANTOS, 2019; DIAS; TAVARES JÚNIOR, 2018), menos ainda sem prejuízos para alguns grupos étnico-raciais, especialmente as mulheres pretas, como se verá neste artigo.

Esclarecemos que a nossa investigação consistiu numa pesquisa exploratória na qual foram coletados e analisados dados quantitativos solicitados à Pró-Reitoria de Ensino (PRE) da UFV e reorganizados pelos autores do presente artigo. Pensamos que os seus resultados são reveladores. Contudo, ante a brevidade que o espaço exige para produção deste artigo, apresentaremos apenas alguns dados, como se verá ao longo do artigo, entre os quais a constatação de que quase não houve ingresso de estudantes pretas do sexo feminino nos cursos supracitados, mesmo havendo políticas públicas orientadas para tal fim.

\section{A Lei das Cotas: o seu surgimento e seus sujeitos de direito}

Em 20 de novembro de 1995, os movimentos negros brasileiros realizam a Marcha Zumbi dos Palmares contra o racismo, pela cidadania e a vida, em Brasília, capital do Brasil. A marcha foi um momento marcante não somente porque colocou trinta mil pessoas na Esplanada dos Ministérios para denunciar o racismo no Brasil. Ela também era propositiva, uma vez que os/as líderes negros/as igualmente reivindicaram políticas públicas contra esse crime e as desigualdades raciais no Brasil, entre as quais "ações afirmativas para acesso dos negros aos cursos profissionalizantes, à universidade e às áreas de tecnologia de ponta" (ENMZ, 1996). 
A marcha também foi relevante porque abriu uma trilha para se incluir a questão racial na agenda política brasileira (cf. SANTOS, 2015). Assim, no início da década seguinte algumas universidades públicas começaram a aprovar e implementar sistema de cotas para estudantes negros/as (pretos/as e pardos/as), como a Universidade do Estado do Rio de Janeiro (UERJ), que o aprovou em 2001 e o implementou em 2002, e a Universidade de Brasília (UnB), que o aprovou em 2003 e o implementou em 2004 (SANTOS, 2015).

A reação discursiva à tentativa de inclusão coletiva de estudantes negros/as nas universidades públicas (que, em geral, são as melhores do país), por meio do sistema de cotas, foi imediata, e não se deu somente por parte de alguns/mas renomados intelectuais, como, por exemplo, Yvonne Maggie e Peter Fry (2004), que lideraram e redigiram manifestos nacionais contra o sistema de cotas étnico-raciais ${ }^{3}$, mas também por parte da grande imprensa que se manifestou radicalmente contra a política de ação afirmativa que se procurava implantar (cf. MOYA, 2014).

Mas houve também reações mais contundentes contra esse sistema. Em setembro de 2009, o Partido Democratas (DEM), de orientação ideológica de direita, ajuizou a Arguição de Descumprimento de Preceito Fundamental (ADPF) no 186 no Supremo Tribunal Federal (STF) contra o sistema de cotas para negros/as da UnB. O DEM, um partido político de raízes escravocratas (cf. SANTOS, 2015), questionou judicialmente a legalidade da política de ação afirmativa da universidade. O STF julgou esta ADPF dois anos e seis meses depois de recebê-la, em abril de 2012, considerando-a improcedente ${ }^{4}$. Isto é, o STF declarou constitucional o sistema de cotas para estudantes negros/as da UnB e, consequentemente, de todas as universidades brasileiras que o haviam implementado (BRASIL, 2012b).

Ao que tudo indica, simultaneamente à decisão do STF, o governo federal brasileiro resolveu apoiar decisivamente, o que não havia feito até então, o Projeto de Lei (PL) № 73, de 24 de fevereiro de 1999, apresentado na Câmara dos Deputados pela então deputada federal Nice Lobão, integrante do extinto Partido da Frente Liberal (PFL) ${ }^{5}$. Este PL estava tramitando no Congresso Nacional há mais de 12 anos, mas quatro meses após o STF decidir positivamente sobre a constitucionalidade do sistema de cotas para negros, a chamada Lei das Cotas (Lei no 12.711/2012) foi aprovada no Congresso Nacional e sancionada pela então Presidente Dilma Rousseff. Portanto, como sustenta Santos (2015, p. 90), "em termos legislativos, a Lei $n=12.711 / 2012$ é fruto do Projeto de Lei (PL) № 73 , de 24 de fevereiro de 1999".

\footnotetext{
Vide, respectivamente, "Todos têm direitos iguais na República Democrática". Disponível em https://www1.folha.uol.com.br/folha/educacao/ult305u18773.shtml. Acesso em 01 jun. 2019, e "Cidadãos Anti-Racistas Contra as Leis Raciais". Disponível em https://www1.folha.uol.com.br/educacao/2008/05/401519-confira-integra-de-manifesto-contracotas-e-quem-o-assinou.shtml. Acesso em 01 jun. 2019.

4 Vide "Acórdão da ADPF 186". Disponível em http://www.stf.jus.br/portal/cms/verNoticiaDetalhe.asp?idConteudo=278000. Acesso em 01 jun. 2019.

${ }^{5}$ O DEM, partido de raízes escravocratas, originou-se do PFL, conforme Santos (2015, p. 23).
} 
Cabe destacar que a Lei $\mathrm{n}^{0}$ 12.711/2012 determinou a implementação do sistema de cotas em todas as Instituições Federais de Ensino Superior (IFES) brasileiras, mas apenas para estudantes de escolas públicas, como se verá abaixo. Antes desta lei, importantes universidades federais se recusavam a implementar sistema de cotas para estudantes pretos/as e pardos/as, como, por exemplo, a Universidade Federal do Rio de Janeiro (UFRJ) e a Universidade Federal de Minas Gerais (UFMG), entre outras. Ao que tudo indica, essas universidades jamais implementariam sistema de cotas para estudantes negros/as e somente implementaram o sistema de cotas para estudantes de escolas públicas a partir de 2013 porque a Lei $\mathrm{n}^{0}$ 12.711/2012 as obrigou6 .

É importante ressaltar que a Lei das Cotas não é para incluir coletivamente estudantes pretos/as, pardos/as e indígenas nas universidades federais, mas incluir significativamente estudantes provenientes de escolas públicas. Aliás, a Lei $n^{0}$ 12.711/2012 prioriza a inclusão dos pobres (sinônimo ${ }^{7}$ de alunos de escolas públicas) nas universidades federais brasileiras. Seu espírito é de "natureza social"8 ou, se se quiser, classista e não racial, ao contrário do que muitos/as acadêmicos/as brasileiros/as contemporaneamente pensam. Para dirimir dúvidas quanto a esta afirmação vamos ao que diz a norma. Segundo a lei,

Art. $1^{\circ}$ As instituições federais de educação superior vinculadas ao Ministério da Educação reservarão, em cada concurso seletivo para ingresso nos cursos de graduação, por curso e turno, no mínimo 50\% (cinquenta por cento) de suas vagas para estudantes que tenham cursado integralmente o ensino médio em escolas públicas. Parágrafo único. No preenchimento das vagas de que trata o caput deste artigo, $50 \%$ (cinquenta por cento) deverão ser reservados aos estudantes oriundos de famílias com renda igual ou inferior a 1,5 salário-mínimo (um salário-mínimo e meio) per capita (...). Art. $3^{\circ}$ Em cada instituição federal de ensino superior, as vagas de que trata 0 art. $1^{\circ}$ desta Lei serão preenchidas, por curso e turno, por autodeclarados pretos, pardos e indígenas e por pessoas com deficiência, nos termos da legislação, em proporção ao total de vagas no mínimo igual à proporção respectiva de pretos, pardos, indígenas e pessoas com deficiência na população da unidade da Federação onde está instalada a instituição, segundo o último censo da Fundação Instituto Brasileiro de Geografia e Estatística - IBGE. Parágrafo único. No caso de não preenchimento das vagas segundo os critérios estabelecidos no caput deste artigo, aquelas remanescentes deverão ser completadas por estudantes que tenham cursado integralmente o ensino médio em escolas públicas (BRASIL, 2012a).

Como se observa no art. $1^{\circ}$ da lei supracitada, estabelece-se nas IFES uma reserva de vagas, ou seja, uma cota de no mínimo $50 \%$ das vagas para estudantes de escolas públicas. Mais ainda, o seu art. 3ำ estabelece uma subcota para pessoas pretas, pardas, indígenas e pessoas com deficiência sobre a cota de $50 \%$ do art. 1ํㅡㄹ em proporção ao total de vagas no mínimo igual à proporção respectiva a esses grupos na população da unidade da Federação onde está instalada a instituição de ensino.

\footnotetext{
${ }^{6}$ Essa afirmação também vale para a UFV, que é objeto de nossa análise no presente artigo, como se verá mais à frente.

${ }^{7} \mathrm{O}$ ministro Gilmar Mendes, do STF, ao manifestar o seu voto na ADPF oㅜ 186, ratifica esse sinônimo. "Claro, nós temos a discussão sobre o modelo da escola pública, que é um referencial, que talvez seja até uma forma de, por figura de linguagem, entender que as pessoas que hoje frequentam, (...), as escolas públicas são, em princípio, pessoas pobres." (MENDES, 2012, p. 5-6).

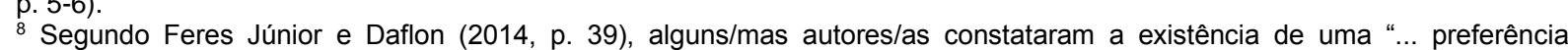
manifestada pelos gestores das universidades pelas políticas de ação afirmativa de natureza social - isto é, que visa estudantes de escolas públicas e/ou baixa renda - e não étnico-racial (...)".
} 
Por conseguinte, a lei e o sistema de cotas que ela institui são, em primeiro lugar, para estudantes que cursaram o ensino médio integralmente em escolas públicas. Somente em segundo lugar ou, se se quiser, num segundo momento em que há as "subcotas" para pessoas pretas, pardas, indígenas e com deficiência. Ou seja, o critério exclusivo para ser sujeito de direito desse sistema de cotas é ser estudante de escola pública. Se o/a estudante não for originário/a de escola pública ele/a não pode ser beneficiário/a do sistema de cotas estabelecido pela Lei ํo 12.711/2012, mesmo sendo preto/a, pardo/a, indígena ou deficiente.

Portanto, e ao contrário do que é comumente propagado, em virtude da lei supracitada, as universidades federais brasileiras implementam um sistema de cotas sociais (para estudante de escola pública) com subcotas étnico-raciais (para pessoas pretas, pardas e indígenas). Aliás, propostas de cotas sociais também foram propostas pelo DEM quando este partido ajuizou a ADFP no 186 no STF, bem como foram defendidas pelo ministro Gilmar Mendes, do STF, quando do julgamento dessa arguição, conforme demonstrou Santos (2015, p. 126-128).

\section{Cursos de alto prestígio e fraudes nas subcotas étnico-raciais}

\section{1 - Tipificando cursos de alto prestígio na Universidade Federal de Viçosa (UFV)}

Como afirmado anteriormente, os/as estudantes cotistas começaram a ingressar na UFV somente a partir do ano de 2013, por determinação da Lei no 12.711/2012. Mais do que isto, tudo indica que, se a lei supracitada não tivesse obrigado a UFV a executar esse tipo de política pública, a instituição não a executaria, o que demonstra que a Universidade também tinha resistências ao sistema de cotas. Também, como visto anteriormente, embora a Lei das Cotas tenha como sujeitos de direito estudantes de escolas públicas, há subcotas étnicoraciais para estudantes pretos/as, pardos/as e indígenas.

Considerando que praticamente não havia estudantes desses grupos étnico-raciais em cursos considerados de alto prestígio das universidades públicas do país (cf. QUEIROZ, 2004 e 2002), procuramos investigar o impacto do ingresso desses estudantes, após a Lei das Cotas, em seis cursos de graduação da UFV, mas de alto prestígio. Visávamos saber se houve aumento significativo no ingresso desses/as estudantes nos cursos supracitados em virtude das subcotas étnico-raciais estabelecidas pela Lei ํㅜ 12.711/2012.

Destacamos que os cursos supracitados não foram designados aleatoriamente por nós como de alto prestígio. Nós nos fundamentamos nos critérios adotados pelo professor João 
Bôsco Hora Góis (2008), segundo o qual se pode delimitar o que e quais são os cursos universitários de graduação mais valorizados com base em dois critérios correlacionados: a valorização no imaginário social e a demanda para ingresso'.

O primeiro deles pode ser chamado de "mérito natural" e está associado ao modo como certas carreiras são percebidas no imaginário social: possuidoras de uma função intrinsecamente relevante e merecedoras de melhores condições de trabalho e assalariamento. (...). Outro critério para atribuição de valor social a um curso é a sua demanda contemporânea e a consequente dificuldade de acesso a ele em função da relação candidato/vaga no vestibular (GÓIS, 2008, p. 746-747).

Associamos mais um critério aos parâmetros indicados pelo pesquisador Góis (2008), qual seja, o fundacional, em face da especificidade da UFV. Por exemplo, os cursos de Agronomia e Medicina Veterinária foram escolhidos por esse critério ${ }^{10}$, pois remontam à criação da Escola Superior de Agricultura e Veterinária (ESAV), em 1926, instituição que deu origem à UFV. Esses dois últimos cursos foram os que impulsionaram a UFV. Além disso, proporcionaram o seu reconhecimento e prestígio ao longo da sua existência, em função da sua reconhecida qualidade, sendo eles prestigiados dentro e fora da universidade, sobretudo porque carregam a tradição de estarem entre os melhores cursos nas áreas de agricultura e veterinária do Brasil.

Já os cursos de Medicina, Direto, Engenharia Química e Engenharia Mecânica foram escolhidos em razão da sua demanda contemporânea e a consequente dificuldade de acesso. Isto é, de acordo com um dos critérios propostos pelo professor Góis (2008), visto que são os cursos mais concorridos da UFV. Eles foram os cursos com maior nota de corte ${ }^{11}$ no processo seletivo do Sistema de Seleção Unificada (SISU) em 2016, embora também sejam cursos valorizados no imaginário social.

\section{2 - Um dos resultados da pesquisa: as subcotas étnico-raciais não garantiram o ingresso significativo de mulheres pretas nos cursos de alto prestígio da UFV}

A nossa pesquisa teve um caráter exploratório, em que foram analisados e/ou construídos dados quantitativos, como citado anteriormente. Estes foram solicitados à Pró-Reitoria de Ensino (PRE) da UFV, visto ser ela a responsável pelo processo de realização de matrícula de todos/as alunos/as de graduação, assim como pela realização dos cálculos de quantas vagas caberão em cada curso para os/as estudantes cotistas e subcotistas étnico-raciais e deficientes, em razão da Lei das Cotas.

Era nossa intenção também produzir dados qualitativos, obtidos e/ou construídos por meio de entrevistas semiestruturadas com alguns/mas estudantes subcotistas étnico-raciais.

\footnotetext{
${ }^{9}$ Edilza Sotero (2013, p. 48) afirma que: “Uma noção acurada de prestígio de cursos de ensino superior no Brasil deve levar em consideração vários fatores, como a concorrência no ingresso, o custo monetário para a permanência no curso, a média de remuneração para os profissionais de determinada carreira, entre outros".

${ }^{10}$ Embora eles também sejam valorizados socialmente, assim como ainda têm elevada demanda.

${ }^{11}$ A nota de corte representa a proporção entre o número de vagas ofertadas e o número de concorrentes a essas vagas. Segundo Queiroz (2004, p. 79), essa medida da demanda para ingresso na universidade também pode funcionar como um "indicador de prestígio do curso".
} 
Porém, devido à dificuldade de entrevistarmos esses/as estudantes, ante sua recusa em nos conceder entrevista, focamos nos dados quantitativos. Porém destacamos que conseguimos entrevistar uma estudante que ingressou na UFV pelas subcotas destinadas aos/às estudantes pretos/as, pardos/as e indígenas, como se verá mais à frente. Mas, enfim, o que os dados "dizem" ou, caso se queira, o que eles nos induzem a pensar?

\subsection{1- A composição sexual dos/as estudantes dos cursos de alto prestígio da UFV, no período de 2013 a 2016}

Antes de adentrarmos diretamente no tema deste item, devemos explicitar que este artigo é mais descritivo que analítico, sendo as nossas análises incipientes por dois fatores básicos. Primeiro, como afirmamos antes, o artigo é fruto de uma pesquisa exploratória, pois se trata de um assunto praticamente não explorado/pesquisado, não havendo conhecimento prévio sobre ele na UFV e nas demais universidades federais brasileiras. Portanto, ao que tudo indica, ainda não há um referencial teórico e metodológico consolidado sobre o impacto do ingresso de estudantes pretos/as e pardos/as em cursos considerados de alto prestígio, o que limita a nossa capacidade de reflexão sobre o assunto. Segundo, ante a brevidade que o espaço exige para produção deste artigo.

Feito o esclarecimento acima e indo direto ao assunto, conforme se pode observar no Quadro 1, de 2013 a 2016, período de nossa investigação, ingressaram na UFV 1.835 estudantes nos cursos de Agronomia, Direito, Engenharia Mecânica, Engenharia Química, Medicina e Medicina Veterinária. Desses/as estudantes, 667 ingressaram pelo sistema de cotas, conforme determina a Lei no $12.711 / 2012$, e 1.168 ingressaram sem fazer opção por este sistema (Quadro 1). Do total de estudantes cotistas, 130 ingressaram na modalidade de estudantes de escola pública com renda menor ou igual a 1,5 salário-mínimo per capita (EEP renda $\leq 1,5$ salário-mínimo), 133 ingressaram na modalidade de estudantes de escola pública com renda maior que 1,5 salário-mínimo per capita (EEP renda > 1,5 salário-mínimo), 210 ingressaram na modalidade e/ou subcota para estudantes pretos/as, pardos/as e indígenas de escola públicas, com renda menor ou igual a 1,5 salário-mínimo per capita (EEP, PPI, renda $\leq 1,5$ salário-mínimo), 194 ingressaram modalidade e/ou na subcota para pretos/as, pardos/as e indígenas de escola públicas, com renda maior que 1,5 salário-mínimo per capita (EEP, PPI, renda > 1,5 salário-mínimo) (Quadro 1). 
Quadro 1 - Quantidade de estudantes dos cursos de alto prestígio da UFV, segundo a cor/raça e a modalidade de ingresso, entre 2013 e 2016.

\begin{tabular}{|c|c|c|c|c|c|c|c|c|}
\hline \multirow[b]{2}{*}{ Modalidade } & \multirow{2}{*}{$\begin{array}{l}\text { Números } \\
\text { exibidos }\end{array}$} & \multicolumn{6}{|c|}{ Cor/raça } & \multirow[t]{2}{*}{ Total } \\
\hline & & Branco & Preto & Pardo & Amarelo & Indígena & $\begin{array}{c}\text { Sem } \\
\text { declaração }\end{array}$ & \\
\hline \multirow{4}{*}{$\begin{array}{c}\mathbf{1} \\
\text { EEP, PPI, renda } \leq 1,5 \\
\text { salário-mínimo }\end{array}$} & Freq. Abs. & 16 & 33 & 149 & 0 & 1 & 11 & 210 \\
\hline & $\%$ Linha & 7,6 & 15,7 & 71,0 & - & 0,5 & 5,2 & 100 \\
\hline & $\%$ Coluna & 1,8 & 28,9 & 24,7 & - & 7,1 & 6,7 & 11,4 \\
\hline & $\%$ Total & 0,9 & 1,8 & 8,1 & - & 0,05 & 0,6 & 11,4 \\
\hline \multirow{4}{*}{$\begin{array}{l}2 \\
\text { EEP, renda } \leq 1,5 \text { salário- } \\
\text { mínimo }\end{array}$} & Freq. Abs. & 98 & 1 & 21 & 1 & 1 & 8 & 130 \\
\hline & \% Linha & 75,4 & 0,8 & 16,1 & 0,8 & 0,8 & 6,1 & 100 \\
\hline & $\%$ Coluna & 10,7 & 0,9 & 3,5 & 3,7 & 7,1 & 4,9 & 7,1 \\
\hline & $\%$ Total & 5,35 & 0,05 & 1,15 & 0,05 & 0,05 & 0,45 & 7,1 \\
\hline \multirow{4}{*}{$\begin{array}{l}3 \\
\text { EEP, PPI, renda }>1,5 \\
\text { salário-mínimo }\end{array}$} & Freq. Abs. & 7 & 28 & 142 & 0 & 2 & 15 & 194 \\
\hline & \% Linha & 3,6 & 14,4 & 73,2 & - & 1,0 & 7,8 & 100 \\
\hline & $\%$ Coluna & 0,9 & 24,6 & 23,5 & - & 14,3 & 9,1 & 10,6 \\
\hline & $\%$ Total & 0,4 & 1,5 & 7,7 & - & 0,1 & 0,8 & 10,6 \\
\hline \multirow{4}{*}{$\begin{array}{c}\mathbf{4} \\
\text { EEP, renda }>1,5 \text { salário- } \\
\text { mínimo }\end{array}$} & Freq. Abs. & 97 & 0 & 24 & 1 & 0 & 11 & 133 \\
\hline & \% Linha & 72,9 & - & 18,0 & 0,8 & - & 8,3 & 100 \\
\hline & $\%$ Coluna & 10,6 & - & 3,9 & 3,7 & - & 6,7 & 7,2 \\
\hline & $\%$ Total & 5,30 & - & 1,30 & 0,05 & - & 0,6 & 7,2 \\
\hline \multirow{4}{*}{$\begin{array}{c}\mathbf{5} \\
\text { Não fez opção pelas cotas }\end{array}$} & Freq. Abs. & 694 & 52 & 268 & 25 & 10 & 119 & 1168 \\
\hline & $\%$ Linha & 59,4 & 4,5 & 22,9 & 2,1 & 0,9 & 10,2 & 100 \\
\hline & $\%$ Coluna & 76,0 & 45,6 & 44,4 & 92,6 & 71,5 & 72,6 & 63,7 \\
\hline & $\%$ Total & 37,8 & 2,8 & 14,6 & 1,35 & 0,55 & 6,5 & 63,7 \\
\hline \multirow{4}{*}{ Total } & Freq. Abs. & 912 & 114 & 604 & 27 & 14 & 164 & 1835 \\
\hline & \% Linha & 49,7 & 6,2 & 32,9 & 1,5 & 0,8 & 8,9 & 100 \\
\hline & $\%$ Coluna & 100 & 100 & 100 & 100 & 100 & 100 & 100 \\
\hline & $\%$ Total & 49,7 & 6,2 & 32,9 & 1,5 & 0,75 & 8,9 & 100 \\
\hline
\end{tabular}

Fonte: Pró-Reitoria de Ensino (PRE)/UFV e dados agregados pelos pesquisadores.

Mais ainda, do total dos/as 1.835 estudantes que ingressaram nos cursos supracitados, $58,7 \%$ eram homens e $41,3 \%$ mulheres (Quadro 2). Observa-se assim uma diferença de $17,4 \%$ entre a quantidade de discentes homens e mulheres, com vantagem numérica e/ou percentual significativa para os estudantes do sexo masculino. Portanto, nos cursos de alto prestígio da UFV havia, no período pesquisado, predominância de estudantes do sexo masculino.

\section{Quadro 2 - Quantidade de estudantes dos cursos de alto prestígio da UFV, segundo o} sexo e a cor/raça dos/as estudantes, entre 2013 e 2016.

\begin{tabular}{|c|c|c|c|c|c|c|}
\hline \multirow{3}{*}{ Cor/raça } & \multicolumn{4}{|c|}{ Sexo } & \multirow{2}{*}{\multicolumn{2}{|c|}{ Total }} \\
\hline & \multicolumn{2}{|l|}{ Masculino } & \multicolumn{2}{|l|}{ Feminino } & & \\
\hline & Frequência absoluta & $\%$ & Frequência absoluta & $\%$ & $\begin{array}{l}\text { Frequência } \\
\text { absoluta }\end{array}$ & $\%$ \\
\hline Brancos/as & 526 & 28,7 & 386 & 21,0 & 912 & 49,70 \\
\hline Pretos/as & 72 & 3,9 & 42 & 2,3 & 114 & 6,20 \\
\hline Pardos/as & 354 & 19,3 & 250 & 13,6 & 604 & 32,90 \\
\hline Negros/as* & 426 & 23,2 & 292 & 15,9 & 718 & 39,10 \\
\hline Amarelos/as & 17 & 0,9 & 10 & 0,6 & 27 & 1,50 \\
\hline Indígenas & 9 & 0,5 & 5 & 0,3 & 14 & 0,80 \\
\hline Sem declaração & 99 & 5,4 & 65 & 3,5 & 164 & 8,90 \\
\hline Total & 1.077 & 58,7 & 758 & 41,3 & 1.835 & 100,0 \\
\hline
\end{tabular}

Fonte: Pró-Reitoria de Ensino (PRE)/UFV e dados agregados pelos pesquisadores.

${ }^{*} A$ categoria negros/as corresponde à soma de pretos/as e pardos/as.

Aparentemente esses dados são divergentes de uma das características do ensino superior brasileiro contemporâneo no que diz respeito à composição sexual dos/as seus/suas discentes de graduação. De acordo com o Censo da Educação Superior de 2016, realizado 
pelo Instituto Nacional de Estudos e Pesquisas Educacionais Anísio Teixeira (INEP), 55,55\% das/os discentes dos cursos de graduação presencial eram mulheres e 44,45\% eram homens (BRASIL, 2016) $^{12}$. Portanto, contemporaneamente, há mais mulheres que homens nos cursos de graduação das universidades brasileiras (BRASIL, 2016).

No período em que foi realizada a pesquisa, a UFV não fugia a essa regra, visto que no segundo semestre de 2016 a universidade tinha 10.281 alunos/as de graduação matriculados/as e estudando efetivamente. Desses/as, 5.236 eram do sexo feminino e 5.045 do sexo masculino, respectivamente, $51 \%$ e $49 \%{ }^{13}$. No segundo semestre de 2015 havia 10.454 alunos/as de graduação matriculados/as e estudando efetivamente na UFV. Desses/as, 5.417 (51,80\%) eram do sexo feminino e 5.037 (48,20\%) do sexo masculino ${ }^{14}$. No segundo semestre de 2014 a universidade tinha 10.505 alunos/as de graduação matriculados/as e estudando efetivamente. Desses/as, 5.496 (52,30\%) eram do sexo feminino e $5.009(47,70 \%)$ do sexo masculino ${ }^{15}$. Essa característica de haver mais estudantes mulheres que homens nos cursos de graduação da UFV era tão expressiva no ano de 2013, quando começou a ser implementado o sistema de cotas na universidade, quanto o foi no ano de 2014, visto que no segundo semestre de 2013 havia 10.415 alunos/as de graduação matriculados/as e estudando efetivamente na UFV, sendo $5.431(52,10 \%)$ do sexo feminino e $4.984(47,90 \%)$ do sexo masculino ${ }^{16}$. Ou seja, no período que delimitamos para realizar nossa pesquisa a maioria dos/as estudantes de graduação da UFV era mulher, corroborando os dados nacionais sobre a composição sexual dos/as estudantes da educação superior brasileira.

Observa-se também que os dados gerais relativos à quantidade de estudantes mulheres e homens que ingressam na UFV são muito semelhantes à quantidade de ambos os sexos na sociedade brasileira, segundo o último Censo Demográfico, realizado pela Fundação Instituto Brasileiro de Geografia e Estatística (IBGE), em 2010, respectivamente 51,03\% e 48,97\% (BRASIL, 2010) (Quadro 3). Tal característica indica uma equivalência proporcional entre a quantidade de mulheres e homens da sociedade brasileira e a quantidade de ingressantes de ambos os sexos nos cursos de graduação da UFV.

Porém, quando desagregamos esses dados, especialmente quando os separamos por cursos, observa-se que a correspondência proporcional "democrática” supracitada é aparente,

\footnotetext{
12 Para maiores informações, ver Tabela 4.06 do documento "Censo da Educação Superior. Principais Resultados, 2016". Disponível em http://download.inep.gov.br/educacao superior/censo superior/documentos/2016/censo superior tabelas.pdf. Acesso em: 08.mai.2018.

${ }^{13}$ Disponível em: <https://www.dti.ufv.br/relatorioufv/>. Acesso em: 08.mai.2018. Obs.: acesse esse link, marque a tabela 16 e selecione o ano de 2016.

${ }_{14}^{14}$ Disponível em: <https://www.dti.ufv.br/relatorioufv/>. Acesso em: 08.mai.2018. Obs.: acesse esse link, marque a tabela $16 \mathrm{e}$ selecione $o$ ano de 2015

${ }^{15}$ Disponível em: <https://www.dti.ufv.br/relatorioufv/>. Acesso em: 08.mai.2018. Obs.: acesse esse link, marque a tabela $16 \mathrm{e}$ selecione o ano de 2014.

${ }^{16}$ Disponível em: <https://www.dti.ufv.br/relatorioufv/>. Acesso em: 08.mai.2018. Obs.: acesse esse link, marque a tabela 16 e selecione o ano de 2014.
} 
visto que os dados agregados "ocultam" um processo de "estratificação de carreiras no ensino superior" (SOTERO, 2013, P. 46). Dito de outra maneira, a correspondência das porcentagens de estudantes mulheres e homens que ingressam na universidade, com as respectivas porcentagens de homens e mulheres na sociedade brasileira, não indica concretamente uma equidade entre esses dois sexos no ensino superior, uma vez que, apesar de ingressarem mais mulheres no ensino superior brasileiro (tendência que também ocorre na UFV) e haver mais mulheres que homens em nossa sociedade, segundo o Censo Demográfico de 2010, isso não significa que as estudantes mulheres também são a maioria dos/as discentes que frequentam e concluem os cursos mais prestigiados das universidades mais importantes do país. Conforme a pesquisadora Edilza Sotero:

\begin{abstract}
Algumas considerações que podem ser feitas, com base no que apontam os dados especificamente sobre ensino superior, são de que as mulheres ingressam em maior quantidade nesta modalidade de ensino, mas o fazem principalmente via IES ${ }^{17}$ privadas e em cursos de menor prestígio. Ao tratar especificamente da mulher negra, observa-se que a sua inserção é menor que a de mulheres brancas, mas os padrões de ingressos - em IES privadas e em cursos de menor prestígio se mantêm (SOTERO, 2013, p. 48-49, grifo nosso).
\end{abstract}

Assim sendo, apesar de estarem em maior quantidade que os homens nos cursos de graduação, as mulheres estão sub-representadas nos cursos considerados de alto prestígio das universidades brasileiras, conforme demonstrou Sotero (2013). Novamente a UFV não foge a essa regra. É o que nos mostram os dados dos/as estudantes, por sexo, dos seis cursos analisados em nossa pesquisa (Quadro 2). Nesses cursos ingressaram mais estudantes homens (58,70\%) que mulheres (41,30\%), implicando desigualdade na composição sexual dos respectivos cursos, com desvantagem significativa para as mulheres (Quadro 2).

\title{
3.2.2- A Composição racial dos/as estudantes dos cursos de alto prestígio da UFV após a implementação da Lei das Cotas
}

Porém, essa desigualdade nos cursos de alto prestígio da UFV não se limita ao sexo dos/as estudantes, uma vez que também são constatadas desigualdades relativas à cor/raça dos/as estudantes. Os dados que obtivemos da universidade indicam que há maior quantidade de discentes brancos/as, que são quase a metade do número total dos/as estudantes dos seis cursos pesquisados/as (49,70\%) no período de 2013 a 2016. Num ranking decrescente, como se verifica no Quadro 1, abaixo dos/as estudantes brancos/as seguem os/as estudantes pardos/as (32,90\%), pretos/as (6,20\%), amarelos/as (1,50\%) e indígenas $(0,80 \%)$. Verifica-se também que há uma considerável quantidade de estudantes sem declaração de cor/raça (8,90\%). Essa última porcentagem é maior que a soma dos percentuais de estudantes pretos/as, indígenas e amarelos/as (8,50\%) nesses cursos.

${ }^{17}$ IES é a sigla de Instituição de Ensino Superior. 
A observação quanto aos estudantes sem declaração de cor/raça no período pesquisado não é aleatória ou sem razão. Em realidade, chamamos a atenção para este fato porque, como se pode observar no Quadro 1, citado anteriormente, havia 11 estudantes que ingressaram na subcota para estudantes pretos(as), pardos(as) e indígenas de escola públicas, com renda menor ou igual 1,5 salário-mínimo per capita (EEP, PPI, renda $\leq 1,5$ salário-mínimo), mas que não declararam a sua cor/raça, assim como havia 15 estudantes que ingressaram na subcota para pretos(as), pardos(as) e indígenas de escola públicas, com renda maior que 1,5 salário-mínimo per capita (EEP, PPI, renda > 1,5 salário-mínimo) na mesma situação ${ }^{18}$.

Como se sabe, e conforme determina a Lei $n^{0}$ 12.711/2012, nas modalidades de ingresso "EEP, PPI, renda $\leq 1,5$ salário-mínimo" e "EEP, PPI, renda > 1,5 salário-mínimo", ou seja, pelas subcotas étnico-raciais, obrigatoriamente deve constar a cor/raça dos/as estudantes para se identificarem os seus sujeitos de direito, ou, caso se queira, para também evitar fraudes. Isto é, para se evitar o ingresso nessas modalidades de estudantes que não são os sujeitos de direito, como, por exemplo, os/as estudantes brancos/as. Mesmo assim, houve no período pesquisado, e ainda há atualmente, tentativas de estudantes brancos/as de fraudar as subcotas étnico-raciais na UFV, bem como em outras universidades federais (cf. DIAS; TAVARES JÚNIOR, 2018).

Devemos lembrar que o movimento negro da cidade Viçosa, onde está localizada um dos campi da UFV, denunciou à universidade que estudantes brancos/as estavam ingressando fraudulentamente nas subcotas étnico-raciais destinadas aos estudantes pretos/as, pardos/as e indígenas ${ }^{19}$. Portanto, é plausível levantar a hipótese de que alguns fraudadores das subcotas étnico-raciais estejam entre os/as estudantes que não declararam a sua cor/raça. Mas, como se verá a seguir, houve também tentativas de fraudes praticadas por estudantes brancos/as que, em geral, se autodeclaravam pardos/as ou indígenas para ingressarem, por meio das subcotas étnico-raciais, nos cursos de alto prestígio da UFV.

\subsubsection{1 - Fraudes nas subcotas étnico-raciais e impactos negativos para estudantes pretas nos cursos de alto prestígio da UFV}

Neste item, em virtude do que indicam os dados nossa pesquisa, objetivamos construir argumentos para sustentar a hipótese de que as estudantes mulheres pretas foram as menos beneficiadas pelas subcotas étnico-raciais, ou seja, foram as que menos impactaram positivamente mudanças na composição racial dos cursos de alto prestígio da UFV. Em razão

\footnotetext{
${ }^{18}$ Neste quadro se observam situações mais graves, como as de estudantes autodeclarados/as brancos/as que ingressaram na UFV pelas subcotas étnico-raciais, algo ilegal, ante a Lei no 12.711/2012, e que será comentado no final do próximo item.

19 Disponível

Disponivel em:

<https://www.facebook.com/NeabVicosaMG/photos/a.1478416349058580.1073741828.1471974029702812/192371199786234

4/?type=3> e em <http://www.folhadamata.com.br/noticia-estudantes-podem-perder-vaga-de-cota-racial-na-ufv-2310>. Acesso em: 01.jun.2019.
} 
de fraudes praticadas por estudantes brancos/as nas subcotas supracitadas, ao que tudo indica, as mulheres pretas sofreram um processo de exclusão no ingresso dos cursos de alto prestígio da UFV. Senão vejamos.

Comparando os dados dos Quadros 1 e 3 pode-se observar que havia uma certa semelhança entre a porcentagem de estudantes brancos/as nos cursos de alto prestígio da UFV (49,70\%) (Quadro 1) e a porcentagem de cidadãos/ãs brancos/as na sociedade brasileira em 2010 (47,70\%) (Quadro 3), mesmo considerando que havia, na época, proporcionalmente mais estudantes brancos/as na UFV. Semelhança que também se verifica quando comparamos a porcentagem de estudantes pretos/as nos referidos cursos de graduação $(6,20 \%$ ) (Quadro 1), com a porcentagem dos/as cidadãos/ãs pretos/as, que era de 7,60\% (Quadro 3), embora, nesse caso, e ao contrário do anterior, havia percentualmente menos estudantes pretos/as nos cursos quando comparados à porcentagem de cidadãos/ãs desse grupo racial na sociedade brasileira.

Contudo, há dados no Quadro 1 que mostram desigualdades étnico-raciais abismais na composição racial dos/as estudantes dos cursos de alto prestígio da UFV, especialmente quando comparados aos dados do Quadro 3. Mais do que isto, eles indicam também que essas desigualdades são fruto de fraudes no sistema de cotas.

\section{Quadro 3 - Distribuição percentual da população residente no Brasil, em 2010, segundo o sexo e a cor/raça.}

\begin{tabular}{|l|c|c|r|}
\hline \multirow{2}{*}{\multicolumn{1}{c|}{ Cor ou raça }} & \multicolumn{2}{|c|}{ Sexo } & \multirow{2}{*}{ Total (\%) } \\
\cline { 2 - 3 } & Homens (\%) & Mulheres (\%) & 47,73 \\
\hline Brancos/as & 22,88 & 24,85 & 7,61 \\
\hline Pretos/as & 3,95 & 3,67 & 43,13 \\
\hline Pardos/as & 21,42 & 21,71 & 50,74 \\
\hline Negros/as & 25,37 & 25,38 & 1,09 \\
\hline Amarelos/as & 0,50 & 0,59 & 0,43 \\
\hline Indígenas & 0,21 & 0,21 & 0,00 \\
\hline Sem declaração & 0,00 & 0,00 & 100,0 \\
\hline \multicolumn{1}{|c|}{ Total } & 48,97 & 51,03 & \\
\hline
\end{tabular}

Fonte: IBGE (2010) e dados agregados pelos pesquisadores.

${ }^{*} \mathrm{~A}$ categoria negros/as corresponde à soma de pretos/as e pardos/as.

Primeiro, os dados do Quadro 1 indicam que os/as estudantes indígenas ( $0,80 \%)$ estão sobre-representados nesses cursos quando comparados à quantidade de cidadãos/ãs indígenas da população brasileira (0,43\%) (Quadro 3). Ou seja, nos cursos de Agronomia, Direito, Engenharia Mecânica, Engenharia Química, Medicina e Medicina Veterinária da UFV havia praticamente o dobro de estudantes autodeclarados/as indígenas comparados à porcentagem de cidadãos/ãs indígenas na sociedade brasileira. Algo aparentemente inexplicável, não somente porque naquela época os indígenas ainda tinham baixa escolaridade quando comparados aos demais grupos étnico-raciais brasileiros (cf. FERRARO, 2011; BASTOS et al., 2017; BRASIL, 2012c), o que limitava significativamente o seu ingresso em universidades públicas, mas também pelo fato de nenhum outro grupo étnico- 
racial de estudantes da UFV apresentar tamanha sobre-representação nesses cursos, nem mesmo os/as estudantes brancos/as, que, em geral, são os mais ricos/as e/ou que estudam em escolas que os/as preparam melhor para ingressarem nas universidades públicas, ao contrário dos/as indígenas, dos/as pretos/as e pardos/as, como indicam algumas pesquisas (cf. RISTOFF, 2014; ARTES, 2012).

Sendo a discrepância supracitada abismal e incomum a qualquer outro grupo étnicoracial brasileiro, é plausível levantar a hipótese de que alguns estudantes se autodeclararam indígenas ${ }^{20}$, mesmo não o sendo (ou seja, não sendo reconhecidos socialmente como tal), com objetivo de ingressar nos cursos de alto prestígio supracitados por meio das subcotas étnico-raciais. Dito de outra maneira, esses/as estudantes, por meio de uma ação racional com relação a fins (cf. WEBER, 1964), se autodeclararam indígenas para terem acesso ao ensino público superior na vaga de estudantes indígenas. Essa maneira de agir, que é uma prática fraudulenta, muito provavelmente também ocorreu nos casos em que estudantes brancos/as se autodeclararam pardos/as para, também, ingressarem nas subcotas étnicoraciais designadas aos estudantes pardos/as, como se verá mais à frente ${ }^{21}$.

Deve-se destacar que não se pode desconhecer que a fraude é um crime. Primeiro porque há o princípio no Direito brasileiro da presunção de conhecimento da lei. Isto é, nenhum/a cidadão/ã pode alegar o desconhecimento da lei ao cometer determinado crime. Conforme estabelece o art. $3^{\circ}$ da Lei de Introdução às normas do Direito Brasileiro: "Ninguém se escusa de cumprir a lei, alegando que não a conhece"22.

Segundo porque, no caso específico, o/a praticante de fraude necessariamente exclui o/a estudante sujeito de direito de uma vaga na universidade. Assim, o/a estudante fraudador/a das subcotas étnico-raciais também pratica discriminação racial (ou o crime de racismo ${ }^{23}$ ) na medida em que impede estudantes pretos/as, pardos/as ou indígenas de terem acesso à universidade para usufruírem direitos garantidos em lei, no caso a Lei no 12.711/2012. Consequentemente esta discriminação racial proporciona desigualdades raciais. Por exemplo, os dados da nossa pesquisa indicam que são as estudantes mulheres pretas as mais afetadas (negativamente) com as fraudes praticadas por estudantes brancos/as. Isto é, os dados nos induzem a ter como hipótese ${ }^{24}$ de trabalho que as estudantes mulheres pretas foram, ao que tudo indica, as mais excluídas e, consequentemente, as mais

\footnotetext{
${ }^{20}$ Até março de 2017 a UFV não possuía "Comissão de verificação de autodeclaração étnico-racial" para aferir a autodeclaração dos estudantes que faziam opção pelas subcotas étnico-raciais. Portanto, bastava o/a estudante se autodeclarar que pertencia a um determinado grupo étnico-racial que a universidade o considerava como tal.

${ }^{21}$ Portanto, não foi sem sentido que a UFV criou a "Comissão de verificação de autodeclaração étnico-racial", por meio do Ato no 08/2017/CEPE, de 13/03/2017, com fins exclusivos de verificar as fraudes no sistema de cotas da universidade.

${ }^{22}$ Disponível em http://www.planalto.gov.br/ccivil 03/decreto-lei/del4657.htm. Acesso em 03 jun. 2019.

${ }^{23}$ Conforme o inciso XLII do art. $5^{\circ}$ da Constituição Brasileira, "A prática do racismo constitui crime inafiançável e imprescritível, sujeito à pena de reclusão, nos termos da lei". Disponível em: $<$ http://www.planalto.gov.br/ccivil 03/constituicao/constituicaocompilado.htm>. Acesso em: 03 jun. 2019. Uma das leis que regulamenta o crime de racismo no Brasil é a Lei $n^{\circ} 7.716$, de 05 de janeiro de 1989, que "Define os crimes resultantes de preconceito de raça ou de cor". Disponível em: <http://www.planalto.gov.br/ccivil 03/leis/l7716.htm>. Acesso em: 03 jun. 2019.

${ }^{24}$ Conforme Giddens (2002), uma hipótese é uma resposta provisória a um problema ou questão.
} 
prejudicadas em razão de fraudes nas subcotas étnico-raciais, visto que quase não havia estudantes mulheres pretas nos cursos de alto prestígio da UFV entre 2013 e 2016. Elas eram apenas 2,30\% do total dos/as estudantes nesses cursos (Quadro 2). ${ }^{25}$

Contudo, a hipótese supracitada adquire robustez quando se constata que a quantidade de estudantes homens brancos (526) dos cursos de Agronomia, Direito, Engenharia Mecânica, Engenharia Química, Medicina e Medicina Veterinária da UFV era 12,5 vezes maior que a de estudantes mulheres pretas (42). A quantidade de mulheres brancas (386) era 9,2 vezes maior que a daquelas, a quantidade de mulheres pardas (250) era 5,95 vezes maior, assim como a de homens pretos era 1,7 vezes maior (Quadro 2). ${ }^{26}$ Assim, ao que os dados indicam, as fraudes nas subcotas étnico-raciais, que geralmente ${ }^{27}$ são praticadas por estudantes brancos/as que se travestem de pardos/as para ingressarem naquelas subcotas (cf. DIAS; TAVARES JÚNIOR, 2018; NUNES; SANTOS, 2019), prejudicaram mais as estudantes mulheres pretas que os homens pretos. Estes também são prejudicados, ou seja, são impedidos de entrarem coletivamente na universidade, especialmente nos cursos de alto prestígio, quando há fraudes nas subcotas étnico-raciais, mas eles não são prejudicados tão intensamente como as estudantes pretas do sexo feminino.

As desigualdades supracitadas parecem ser mais abismais quando visualizamos os dados desagregados por curso. Todavia, ante a brevidade que o espaço exige para produção deste artigo, descreveremos os dados de um curso, o de Medicina, e faremos uma incipiente análise desses dados. Deve-se lembrar que o curso de Medicina é um dos mais demandados pelos/as candidatos a uma vaga na universidade, em virtude da razão candidato por vaga, inclusive na UFV.

Assim, no período pesquisado, de 2013 a 2016, ingressaram na UFV 200 estudantes nesse curso, sendo 107 homens (53,50\%) e 93 mulheres (46,50\%). Daquele total, 81 $(40,50 \%)$ se autodeclararam brancos/as, 5 (2,50\%) pretos/as, 57 (28,50\%) pardos/as, $2(1 \%)$ amarelos, 4 (2\%) indígenas e 51 (25,50\%) sem declaração de cor/raça (Quadro 4). Também é possível constatar nesse quadro que $21 \%$ dos estudantes do curso de Medicina eram homens brancos, $19,50 \%$ eram mulheres brancas, $16 \%$ eram homens pardos, $12,50 \%$ eram mulheres pardas, $13 \%$ eram homens sem declaração de cor/raça, 12,50\% eram mulheres

\footnotetext{
${ }^{25}$ Deve-se lembrar que entre 2013 e 2016, período de nossa pesquisa, não havia na UFV a fiscalização da política pública estabelecida pela Lei 12.711/2012, o sistema de cotas, por meio das "Comissões de verificação de autodeclaração étnico-racial". Estas, atualmente, aferem a autodeclaração de identidade racial dos/as estudantes que fazem opção pelas subcotas étnicoraciais para ingressarem na universidade. Naquela época, bastava a autodeclaração do/a estudante para caracterizá-lo ou identificá-lo como pertencente a uma determinada cor/raça, momento em que muitos estudantes brancos/as se travestiam de pardos/as para obter uma vaga nas subcotas étnico-raciais.

${ }^{26}$ Isso não significa que as estudantes indígenas também não estivessem sendo excluídas desses cursos em razão de fraudes. Aliás, como mostramos anteriormente, havia elevada probabilidade de que algumas estudantes brancas se autodeclarassem indígenas para ingressarem nas subcotas étnico-raciais. Ante a isso, entre outros fatos, pode-se argumentar que a quantidade de mulheres pretas nesses cursos era maior que a de indígenas. Contudo, conforme demonstrado anteriormente, naquela época havia menor probabilidade de ingresso de estudantes indígenas nos cursos superiores de universidades públicas do que de mulheres pretas. Ou seja, havia maior probabilidade de essas ingressarem em maior quantidade nessas universidades quando comparado com aquelas. Por isso a nossa hipótese é focada nas estudantes mulheres pretas.

${ }^{27}$ Afirmamos que é geralmente por estudantes brancos/as porque ela, a fraude, também pode ser praticada por estudantes amarelos/as.
} 
dessa mesma categoria, $2 \%$ eram homens pretos, $0,50 \%$ era mulher preta, $1 \%$ era homem amarelo, 0,50\% era homem indígena e 1,50\% era mulher indígena.

Quadro 4 - Quantidade dos/as estudantes do curso de Medicina da UFV, segundo o sexo e a cor/raça, entre 2013 e 2016.

\begin{tabular}{|c|c|c|c|c|c|c|}
\hline \multirow{3}{*}{ Cor/raça } & \multicolumn{4}{|c|}{ Sexo } & \multirow{2}{*}{\multicolumn{2}{|c|}{ Total }} \\
\hline & Homens & & Mulheres & & & \\
\hline & Frequência absoluta & $\%$ & Frequência absoluta & $\%$ & Frequência absoluta & $\%$ \\
\hline Brancos/as & 42 & 21 & 39 & 19,5 & 81 & 40,5 \\
\hline Pretos/as & 4 & 2 & 1 & 0,5 & 5 & 2,5 \\
\hline Pardos/as & 32 & 16 & 25 & 12,5 & 57 & 28,5 \\
\hline Amarelos/as & 2 & 1 & 0 & 0 & 2 & 1 \\
\hline Indígenas & 1 & 0,5 & 3 & 1,5 & 4 & 2 \\
\hline Sem declaração & 26 & 13 & 25 & 12,5 & 51 & 25,5 \\
\hline Total & 107 & 53,5 & 93 & 46,5 & 200 & 100 \\
\hline
\end{tabular}

Fonte: Pró-Reitoria de Ensino (PRE)/UFV e dados agregados pelos autores.

Como se pode constatar, esses dados indicam não somente uma baixíssima presença de mulheres pretas (0,50\%) no curso de Medicina da UFV, mesmo após a Lei no 12.711/2012, mas também uma discrepância que não é comum no ensino público superior brasileiro: havia três (3) vezes mais estudantes mulheres indígenas que mulheres pretas (1) no curso. Mais ainda, por um lado, considerando que o curso de Medicina é, geralmente, o mais concorrido nas universidades brasileiras, mas, especialmente, considerando que as estudantes mulheres indígenas, em geral, têm, em média, mais baixa escolaridade que as mulheres pretas, os dados estão indicando não somente a alta probabilidade de fraude nas cotas étnico-raciais, como também o quanto as estudantes mulheres pretas foram e ainda têm sido excluídas dos cursos de alto prestígio das universidades em razão de fraudes.

Por outro lado, ratificando a assertiva anterior, no período de $2013^{28}$ a $2016^{29}$ verificase que não houve aumento no ingresso de estudantes mulheres pretas no curso de Medicina. Isto é, ingressou apenas uma estudante preta nesse curso no ano de 2013 e não ingressou mais nenhuma até o ano de 2016 (Quadro 5), mesmo tendo aumentado o número de vagas nas subcotas étnico-raciais, ano após ano. Assim, para as mulheres pretas houve taxa média de crescimento acumulado negativa de $-100 \%{ }^{30}$. Por outro lado, o ingresso de homens pardos no curso de Medicina mais que dobrou no mesmo período, passando de 05, em 2013, para 11 ingressantes, em 2016 (Quadro 5), tendo uma taxa média de crescimento acumulado de $21,79 \%$.

\footnotetext{
${ }^{28}$ Ano em que começou a implementação, parcialmente, do sistema de cotas na UFV, como visto antes.

${ }^{29}$ Ano em que a implementação do sistema cotas na UFV foi concluída, ou seja, atingiu sua integralidade, como visto antes.

${ }^{30} \mathrm{O}$ cálculo foi feito pelo software CAGR Calulator. Disponível em: <https://cagrcalculator. net/result/>. Acesso em: 03 jun. 2019.

${ }^{31} \mathrm{O}$ cálculo foi feito pelo software CAGR Calulator. Disponível em: <https://cagrcalculator.net/result/>. Acesso em: 03 jun. 2019.
} 


\section{Quadro 5 - Quantidade dos/das estudantes do curso de Medicina da UFV, segundo o sexo, a cor/raça e o ano de ingresso, entre 2013 e 2016.}

\begin{tabular}{|c|c|c|c|c|c|c|c|c|c|c|c|c|c|c|c|c|c|c|c|c|c|c|c|c|}
\hline \multirow{5}{*}{ Cor/raça } & \multicolumn{24}{|c|}{ Ano } \\
\hline & \multirow{2}{*}{\multicolumn{6}{|c|}{$\begin{array}{l}2013 \\
\text { Sexo }\end{array}$}} & \multirow{2}{*}{\multicolumn{6}{|c|}{$\begin{array}{l}2014 \\
\text { Sexo } \\
\end{array}$}} & \multirow{2}{*}{\multicolumn{6}{|c|}{$\begin{array}{l}2015 \\
\text { Sexo } \\
\end{array}$}} & \multirow{2}{*}{\multicolumn{6}{|c|}{$\begin{array}{l}2016 \\
\text { Sexo }\end{array}$}} \\
\hline & & & & & & & & & & & & & & & & & & & & & & & & \\
\hline & \multicolumn{2}{|c|}{ Homens } & \multicolumn{2}{|c|}{ Mulheres } & \multicolumn{2}{|c|}{ Total } & \multicolumn{2}{|c|}{ Homens } & \multicolumn{2}{|c|}{ Mulheres } & \multicolumn{2}{|c|}{ Total } & \multicolumn{2}{|c|}{ Homens } & \multicolumn{2}{|c|}{ Mulheres } & \multicolumn{2}{|c|}{ Total } & \multicolumn{2}{|c|}{ Homens } & \multicolumn{2}{|c|}{ Mulheres } & \multicolumn{2}{|c|}{ Total } \\
\hline & F.A. & $\%$ & $\mathrm{~N}$ & $\%$ & $\mathrm{~N}$ & $\%$ & $\mathrm{~N}$ & $\%$ & $\mathrm{~N}$ & $\%$ & $\mathrm{~N}$ & $\%$ & $\mathrm{~N}$ & $\%$ & $\mathrm{~N}$ & $\%$ & $\mathrm{~N}$ & $\%$ & $\mathrm{~N}$ & $\%$ & $\mathrm{~N}$ & $\%$ & $\mathrm{~N}$ & $\%$ \\
\hline Brancos/as & 11 & 22,0 & 14 & 28,0 & 25 & 50,0 & 8 & 16,0 & 8 & 16,0 & 16 & 32,0 & 7 & 14,0 & 8 & 16,0 & 15 & 30,0 & 16 & 32,0 & 9 & 18,0 & 25 & $\begin{array}{c}50, \\
0\end{array}$ \\
\hline Pretos/as & 2 & 4,0 & 1 & 2,0 & 3 & 6,0 & 0 & - & 0 & - & 0 & - & 1 & 2,0 & 0 & - & 1 & 2,0 & 1 & 2,0 & 0 & - & 1 & 2,0 \\
\hline Pardos/as & 5 & 10,0 & 9 & 18,0 & 14 & 28,0 & 4 & 8,0 & 6 & 12,0 & 10 & 20,0 & 12 & 24,0 & 5 & 10,0 & 17 & 34,0 & 11 & 22,0 & 5 & 10,0 & 16 & $\begin{array}{c}32, \\
0\end{array}$ \\
\hline Amarelos/as & 1 & 2,0 & 0 & - & 1 & 2,0 & 1 & 2,0 & 0 & - & 1 & 2,0 & 0 & - & 0 & - & 0 & - & 0 & - & 0 & - & 0 & - \\
\hline Indígenas & 1 & 2,0 & 3 & 6,0 & 4 & 8,0 & 0 & - & 0 & - & 0 & - & 0 & - & 0 & - & 0 & - & 0 & - & 0 & - & 0 & - \\
\hline $\begin{array}{c}\text { Sem } \\
\text { declaração }\end{array}$ & 2 & 4,0 & 1 & 2,0 & 3 & 6,0 & 11 & 22,0 & 12 & 24,0 & 23 & 46,0 & 8 & 16,0 & 9 & 18,0 & 17 & 34,0 & 5 & 10,0 & 3 & 6,0 & 8 & $\begin{array}{c}16, \\
0 \\
\end{array}$ \\
\hline Total & 22 & 44,0 & 28 & 56,0 & 50 & 100 & 24 & 48,0 & 26 & 52,0 & 50 & 100 & 28 & 56,0 & 22 & 44,0 & 50 & 100 & 33 & 66,0 & 17 & 34,0 & 50 & 100 \\
\hline
\end{tabular}

Fonte: Pró-Reitoria de Ensino (PRE)/UFV e dados agregados pelos autores.

Considerando a taxa média de crescimento acumulado dos estudantes homens pardos no curso de Medicina ao longo do período pesquisado, assim como considerando os objetivos desse artigo, não é demais lembrar que é na categoria "Pardos/as" que se têm concentrado as tentativas de burla nas autodeclarações étnico-raciais (cf. NUNES; SANTOS, 2019; DIAS; TAVARES JÚNIOR, 2018). A própria UFV comprova, empiricamente, a afirmação acima ao registrar este fato em um dos seus mais importantes documentos oficiais, uma ata do Conselho de Ensino, Pesquisa e Extensão (CEPE) da UFV, qual seja, a ATA/CEPE 532, de 25 de maio de 2017. Neste documento consta que, dos/as vinte e cinco estudantes que foram desligados da universidade em razão de fraudes nas subcotas étnico-raciais, 100\% deles/as o foram porque "não se enquadra[vam] na condição de pessoa parda". Desses/as estudantes, $12 \%$ eram do curso de Medicina (BRASIL, 2017a).

Para finalizar este item, gostaríamos de apresentar pelo menos mais um fato que, ao que tudo indica, também demonstra a plausibilidade da nossa hipótese sobre as fraudes nas subcotas étnico-raciais dos cursos de alto prestígio da UFV e suas consequências, entre as quais a de que este crime prejudicou mais as estudantes mulheres pretas que os estudantes pretos do sexo masculino.

Visando corroborar o que alguns dados indicavam (como, por exemplo, fraude e/ou irregularidades nas subcotas étnico-raciais) ou até mesmo questionar e/ou corrigir a nossa hipótese de fraude nas subcotas, procuramos realizar entrevistas qualitativas com alguns/mas estudantes que ingressaram nessa modalidade, mas que constava oficialmente que se autodeclararam brancos/as e/ou que não constava a sua declaração de cor. Por exemplo, no Quadro 1, citado anteriormente, se observam, ao que tudo indica, duas irregularidades gritantes. A primeira, do total (210) de alunos/as dos cursos de alto prestígio que ingressaram na UFV, entre 2013 e 2016, na modalidade e/ou subcota para estudantes pretos/as, pardos/as e indígenas de escola públicas, com renda menor ou igual a 1,5 salário-mínimo per capita (EEP, PPI, renda $\leq 1,5$ salário-mínimo), 16 deles/as ou 7,60\% se autodeclararam brancos/as. Do mesmo modo, se observa que do total (194) dos/as alunos/as que ingressaram na subcota 
para pretos/as, pardos/as e indígenas de escola públicas, mas com renda maior que 1,5 salário-mínimo per capita (EEP, PPI, renda > 1,5 salário-mínimo), 07 deles/as ou 3,60\% se autodeclararam brancos/as.

A segunda irregularidade pode ser observada nessas mesmas modalidades de ingresso, mas na categoria sem declaração de cor, como citado no final do item 2.2.2, mas que repetiremos aqui. Na primeira modalidade supracitada, EEP, PPI, renda $\leq 1,5$ saláriomínimo, havia 11 ou $5,20 \%$ estudantes que não tinham declarado a sua cor/raça, embora fosse obrigatório declará-la, em virtude da Lei das Cotas. Já na segunda modalidade supracitada, EEP, PPI, renda > 1,5 salário-mínimo, havia 15 ou 7,80\% estudantes que não tinham declarado a sua cor/raça. Ou seja, havia aqui uma falha grave da instituição, pois a universidade tinha a obrigação de obter esta informação dos/as estudantes, em virtude da Lei das Cotas.

Observa-se assim que havia um total de 26 estudantes sem cor/raça declarada, assim como 23 autodeclarados/as brancos/as que ingressaram na UFV por meio das subcotas étnico-raciais destinadas aos/às estudantes pretos/as, pardos/as e indígenas (Quadro 1). Ou seja, nos cursos de alto prestígio da UFV, durante o período de 2013 a 2016, havia um total de 49 estudantes em situação, ao que tudo indica, ilegal, conforme dados informados pela Pró-Reitoria de Ensino (PRE), que foram organizados e/ou agregados por nós.

Para verificar se de fato os dados supracitados demonstravam irregularidades ou ilegalidades, tentamos entrevistar os/as 49 estudantes supracitados, por meio um roteiro previamente elaborado. Ou seja, por meio de uma entrevista semiestruturada ou semidiretiva. Assim, demandamos à PRE que enviasse e-mails para este grupo de estudantes ${ }^{32}$ comunicando sobre a nossa pesquisa e, mais ainda, que gostaríamos de entrevistá-los/as. Antes de enviar os e-mails aos/às estudantes, a PRE conferiu a situação estudantil de todos/as 49 estudantes indicados por nós e constatou que vinte e oito deles/as haviam abandonado os seus cursos, um/a havia sido desligado da universidade e um/a havia concluído o seu curso, restando, portanto, 19 deles/as na UFV.

Assim sendo, a PRE enviou e-mails apenas para esses/as dezenove estudantes, solicitando que nos concedem uma entrevista. Do total de e-mails enviados pela PRE, quatorze foram para estudantes autodeclarados/as brancos/as, mas que ingressaram na UFV por meio das subcotas étnico-raciais de EEP, PPI, renda $\leq 1,5$ salário-mínimo, e cinco e-mails foram enviados para estudantes que ingressaram na universidade por meio das subcotas étnico-raciais de EEP, PPI, renda > 1,5 salário-mínimo. Desses últimos e-mails, quatro foram enviados para estudantes que se autodeclaram brancos/as e um enviado para um/a estudante que não havia declarado a sua cor/raça.

\footnotetext{
${ }^{32}$ Visto que não os/as conhecíamos, não sabíamos os seus nomes, bem como não tínhamos os seus contatos. Eles/as eram "números" fornecidos a nós pela PRE.
} 
Os e-mails foram enviados três vezes aos/às dezenove estudantes, num intervalo de um mês. Por meio dos e-mails a PRE informava sobre a nossa pesquisa, fornecia o nosso contato e solicitava aos/às estudantes que nos contactassem para a concessão de uma entrevista sobre o tema da pesquisa. Apenas uma estudante de um dos cursos do Centro de Ciências Biológicas e da Saúde (CCB) respondeu à solicitação da PRE demonstrando interesse em participar da pesquisa. Portanto, ela foi a única estudante que nos concedeu entrevista $^{33}$. Ante a brevidade que o espaço exige para produção deste artigo, assim como os seus objetivos, não descreveremos e/ou analisaremos toda a entrevista que essa estudante nos concedeu. Comentaremos apenas um item, o relativo à sua classificação racial.

Por meio da entrevista, e ratificando o que os dados indicavam, constatamos que se tratava de uma estudante que ingressou na UFV através da modalidade das subcotas étnicoraciais para estudantes pretos/as, pardos/as e indígenas com renda $\leq 1,5$ salário-mínimo per capita. Mais ainda, ao ser perguntada como ela se autoclassificava racialmente, a entrevistada declarou ser parda. Segundo a própria entrevistada: "Nossa ..., não sei [como me autoclassificar racialmente]. Às vezes eu acho que sou parda, mas eu tenho muita dúvida nessa questão (risos). Mas eu me autodeclaro parda. Porque eu não sou tão branquinha; [mas] não negra. Não sei (risos)". Porém, a entrevistadora, uma estudante de um dos cursos do Centro de Ciências Humanas, Letras e Artes (CCH) da UFV, que se autodeclara e é reconhecida socialmente como branca, identificou a entrevistada como (racialmente) branca, sem tergiversar, e não como parda.

Pensamos que a informação acima é mais uma evidência de que foram estudantes brancos/as que fraudaram as subcotas étnico-raciais, autodeclarando-se pardos/as ${ }^{34}$ e, consequentemente, se apropriaram das vagas destinadas a estudantes pretos/as, pardos/as e indígenas, visto que na época a UFV não fiscalizava o ingresso dos/as candidatos/as às subcota étnico-raciais por meio das "Comissões de verificação de autodeclaração étnicoracial". Estas somente foram criadas em março de 2017, após as denúncias de fraudes no sistema de cotas feitas pelo movimento negro da cidade de Viçosa.

Mais ainda, quando a entrevistada afirma que "...eu me autodeclaro parda. Porque eu não sou tão branquinha; [mas] não negra", ao que tudo indica, ela sabe que a vaga que ela está ocupando era para candidatas negras, isto é, pretas ou pardas. Não somente isso, as suas dúvidas quanto à classificação racial podem até ser reais, mas parecem se dissipar quando ela mesma afirma que ela não é "tão branquinha". Ou seja, ao que tudo indica, ela

\footnotetext{
33 Não citamos o curso da estudante entrevistada e da entrevistadora para não proporcionar qualquer possibilidade de identificação delas, em face do nosso compromisso de pesquisa e/ou princípio ético de manter o anonimato dos/as estudantes que participaram da nossa pesquisa. Como se observa também, não fomos nós que realizamos a entrevista com a entrevistada. Buscando neutralidade durante o processo de pesquisa e, consequentemente, evitar a possibilidade de "viciá-la", pensamos ser mais apropriado que outro/a acadêmico/a fizesse a entrevista.

${ }^{34} \mathrm{Ou}$ até mesmo autodeclarando-se indígenas, em face da desproporcional porcentagem de estudantes dos cursos de alto prestígio que se autodeclararam indígenas, como visto anteriormente.
} 
sabe que é branca, embora não "tão branca". Mais do que isso, ao que parece, ela tem consciência de quem ela retirou a vaga quando afirma que não é negra.

\section{Considerações finais}

Os dados e/ou fatos apresentados neste artigo indicam que, apesar de o sistema de cotas começar a ser implementado a partir de 2013 na UFV, em razão da Lei das Cotas, isso não implicou um aumento expressivo de estudantes autodeclarados/as (e reconhecidos/as socialmente como) pretos/as nos seis cursos pesquisados e considerados de alto prestígio na UFV. Ao analisarmos a admissão dos/as estudantes que ingressaram na universidade por meio das subcotas étnico-raciais, entre 2013 e 2016, constatamos, por meio de dados fornecidos pela própria universidade (portanto, dados oficiais), que o ingresso coletivo dos/as estudantes pretos/as nos seis cursos de alto prestígio da UFV não foi significativo, isto é, quantitativamente crescente, ao contrário do que se esperava.

Mais ainda, os dados indicam que as estudantes mulheres pretas foram as menos beneficiadas com a implementação das subcotas étnico-raciais. A baixíssima quantidade dessas estudantes nos seis cursos pesquisados indica que elas não conseguiram ingressar em quantidade significativa nesses cursos, mesmo depois da implementação de uma lei que Ihes proporcionava tratamento diferenciado para tal. Ao que tudo indica, elas foram prejudicadas em face de fraudes praticadas por estudantes brancos/as. Por exemplo, em razão das fraudes, as mulheres pretas tiveram até taxa média de crescimento acumulado negativa no curso de Medicina, no período pesquisado, como visto anteriormente.

O mesmo não se pode afirmar em relação aos estudantes homens pardos. Os dados indicam que eles tiveram ingresso positivo nos cursos pesquisados, ou seja, quantitativamente crescente o longo do período pesquisado, especialmente no curso de Medicina. Tais fatos, antes de indicar o funcionamento adequado do sistema de cotas da UFV, uma vez que os/as estudantes pardos/as também são um dos sujeitos de direito das subcotas étnico-raciais estabelecidas pela Lei no 12.711/2012, ao que parece, estão a indicar uma alta probabilidade de fraude nestas subcotas, visto que é na categoria "Pardo/a" que se têm concentrado as tentativas de burla nas autodeclarações étnico-raciais, conforme indicam pesquisas sobre o tema, bem como comprovou empiricamente a UFV ao desligar estudantes brancos/as que "não se enquadra[vam] na condição de pessoa parda". 


\section{Referências}

ANDIFES, Associação Nacional dos Dirigentes das Instituições Federais de Ensino Superior. V Pesquisa do Perfil Socioeconômico e Cultural dos Estudantes de Graduação das Universidades Federais. Uberlândia: Andifes/Fonaprace, 2019.

ARTES, Amélia. $O$ ensino médio como filtro para o acesso de negros no ensino superior brasileiro. Revista da ABPN, 8(19), pp. 34-51, 2016.

BASTOS, João. L. et al. Características sociodemográficas de indígenas nos censos brasileiros de 2000 e 2010: uma abordagem comparativa. Cad. Saúde Pública, 33(1), pp. 217, 2017.

BRASIL, UFV. ATA/CEPE 532, de 25 de maio de 2017a. Disponível em: http://www.soc.ufv.br/wp-content/uploads/05-ATA-CEPE-532-25.05.17.pdf. Acesso em: 01.jun. 2019.

BRASIL, UFV. ATA/CEPE 534, de 16 de agosto de 2017b. Disponível em: http://www.soc.ufv.br/wp-content/uploads/07-ATA-CEPE-534-16.08.17.pdf. Acesso em: 01.jun. 2019.

BRASIL, UFV. ATA/CEPE 540, de 20 de dezembro de 2017c. Disponível em: http://www.soc.ufv.br/wp-content/uploads/13-ATA-CEPE-540-20.12.17.pdf. Acesso em: 01.jun. 2019.

BRASIL, Instituto Nacional de Estudos e Pesquisas Educacionais Anísio Teixeira (INEP). Censo da educação superior. Principais resultados, 2016. Brasília: INEP, 2016.

BRASIL. Lei no 12.711, de 29 de agosto de 2012, 2012a. Disponível em: http://www.planalto.gov.br/ccivil 03/ ato2011-2014/2012/lei//12711.htm. Acesso em: 01.jun. 2019.

BRASIL, Supremo Tribunal Federal (STF). Acórdão da ADPF 186, de 25 e 26 de abril de 2012, 2012b. Disponível em:

http://www.stf.jus.br/portal/cms/verNoticiaDetalhe.asp?idConteudo=278000. Acesso em: 01.jun.2019.

BRASIL, Fundação Instituto Brasileiro de Geografia e Estatística (IBGE). Censo demográfico 2010: características gerais dos indígenas, resultados do universo. Rio de Janeiro: IBGE, $2012 c$.

https://biblioteca.ibge.gov.br/visualizacao/periodicos/95/cd 2010 indigenas universo.pdf. Acesso em: 01.jun.2019.

BRASIL, Fundação Instituto Brasileiro de Geografia e Estatística (IBGE). Censo demográfico 2010. Brasília: $\quad$ IBGE, 2010.2 Disponível em: https://ww2.ibge.gov.br/home/estatistica/populacao/censo2010/caracteristicas da populaca o/default caracteristicas da populacao.shtm. Acesso em 08.mai.2018.

DIAS, Gleidson; TAVARES JÚNIOR, Paulo. R. F. Heteroidentificação e cotas raciais: dúvidas, metodologias e procedimentos. Canoas: IFRS campus Canoas, 2018. 
ENMZ, Executiva Nacional da Marcha Zumbi. Por uma política nacional de combate ao racismo e à desigualdade racial: marcha Zumbi contra o racismo, pela cidadania e vida. Brasília: Cultura Gráfica e Ed, 1996.

FERES JÚNIOR, João; DAFLON, Verônica T. Políticas da igualdade racial no ensino superior. Revista Cadernos do Desenvolvimento Fluminense, (5), pp. 31-43, 2014.

FERRARO, Alceu. R. Alfabetização e escolarização em terras indígenas no Brasil nas décadas de 1990 e 2000. Cadernos de Educação, 40, pp. 4-26, 2011.

GIDDENS, Anthony. Modernidade e identidade. Rio Janeiro: Jorge Zahar, 2002.

GÓIS, João B. H. Quando raça conta: um estudo de diferenças entre mulheres brancas e negras no acesso e permanência no ensino superior. Revista Estudos Feministas, 16(3), pp. 743-768, 2008.

HERNÁNDEZ, Tanya Katerí. Subordinação racial no Brasil e na América Latina: o papel do Estado, o Direito Costumeiro e a Nova Resposta dos Direitos Civis. Salvador: EDUFBA, 2017.

MAGGIE, Yvonne. Prefácio. In: KAMEL, Ali. Não somos racistas: uma reação aos que querem nos transformar numa nação bicolor. Rio de Janeiro: Nova Fronteira, 2006, pp. 913.

MAGGIE, Yvonne; FRY, Peter. A reserva de vagas para negros nas universidades brasileiras. Estudos Avançados, 18(50), pp. 67-80, 2004.

MENDES, Gilmar. Voto relativo à ADPF no 186. In: BRASIL. STF. Acórdão da ADPF 186 de 25 e 26 de abril de 2012, 2012. Disponível em: http://www.stf.jus.br/portal/cms/verNoticiaDetalhe.asp?idConteudo=278000. Acesso em: 01.jun.2019.

MOYA, Thais. A cota da mídia. Análise da repercussão das ações afirmativas em jornais e revistas. Jundiaí: Paco Editorial, 2014.

NUNES, Georgina H. L.; SANTOS, Sales A. dos. Sistema de cuotas, fraudes e híperracismo en Brasil. Revista Mexicana de Sociología, 81(3), pp. 637-663, 2019.

QUEIROZ, Delcele M. O negro e a universidade brasileira. História Actual Online, (3), pp. 73-82, 2004.

QUEIROZ, Delcele M. O negro na universidade. Publicação do Programa A Cor da Bahia/Programa de Pós-Graduação em Ciências Sociais da Faculdade de Filosofia e Ciências Humanas da UFBA. Salvador: Novos Toques, 2002.

RISTOFF, Dilvo. O novo perfil do campus brasileiro: uma análise do perfil socioeconômico do estudante de graduação. Avaliação, 19(3), pp. 723-747, 2014.

SANTOS, Sales A. dos. O sistema de cotas para negros da UnB: um balanço da primeira geração. Jundiaí: Paco Editorial, 2015. 
SOTERO, Edilza. Transformações no acesso ao ensino superior brasileiro: algumas implicações para os diferentes grupos de cor e sexo. In: M. M. Marcondes et al. (org.). Dossiê mulheres negras: retrato das condições de vida das mulheres no Brasil. Brasília: IPEA, pp. 35-52, 2013.

WEBER, Max. Economía y sociedad. México: Fondo de Cultura Económica, 1964. 